\title{
Determination and interpretation of surface and atmospheric Miniature Thermal Emission Spectrometer spectral end-members at the Meridiani Planum landing site
}

\author{
Timothy D. Glotch ${ }^{1,2}$ and Joshua L. Bandfield ${ }^{3}$ \\ Received 29 December 2005; revised 24 April 2006; accepted 4 May 2006; published 4 October 2006.
}

[1] Factor analysis and target transformation techniques have been applied to Miniature Thermal Emission Spectrometer (Mini-TES) spectra to isolate the end-member surface and atmospheric component spectral shapes at Meridiani Planum. The surface spectral shapes recovered from the Mini-TES data set include coarse, gray hematite, surface dust, basaltic sand, and the silica/sulfate-rich outcrop. In addition, two atmospheric spectral shapes are identified, indicating the variable nature of the atmosphere over the course of the MER rover missions. Linear deconvolution of the basaltic spectral shape indicates that it is high in plagioclase and pyroxene, including pigeonite, with smaller amounts of glass/ phyllosilicate and olivine. Linear deconvolution of the outcrop spectral shape indicates that it is composed primarily of amorphous silica/glass/phyllosilicates and $\mathrm{Mg}-, \mathrm{Ca}-$, and Fe-bearing sulfates, with smaller amounts of plagioclase.

Citation: Glotch, T. D., and J. L. Bandfield (2006), Determination and interpretation of surface and atmospheric Miniature Thermal Emission Spectrometer spectral end-members at the Meridiani Planum landing site, J. Geophys. Res., 111, E12S06, doi:10.1029/2005JE002671.

\section{Introduction}

[2] The Mars Exploration Rover (MER) Opportunity landed at Meridiani Planum on 24 January 2004 inside Eagle crater [Squyres et al., 2004]. The Opportunity landing site was chosen largely based on the detection of gray crystalline hematite by the orbital Thermal Emission Spectrometer (TES) instrument [Christensen et al., 2000, 2001] which is associated with abundant layered deposits [Edgett and Parker, 1997; Christensen et al., 2000; Hynek et al., 2002; Arvidson et al., 2003; Christensen and Ruff, 2004; Edgett, 2005] and the perceived safety of the landing area [Golombek et al., 2003, 2005]. The scene in Eagle crater imaged by the Pancam [Bell et al., 2004], Microscopic Imager [Herkenhoff et al., 2004], and the engineering cameras [Maki et al., 2003] showed a surface dominated by fine, dark sand, with occurrences of a light toned outcrop having gray spherules within it and on its surface that average 2-5 $\mathrm{mm}$ in diameter [Soderblom et al., 2004] (Figure 1). The Miniature Thermal Emission Spectrometer (Mini-TES) has observed surfaces dominated by each of these components, but given the 20 mrad spot size of the Mini-TES instrument it has been difficult to acquire spectra of pure components [Christensen et al., 2004]. Spectra of

\footnotetext{
${ }^{1}$ Division of Geological and Planetary Science, California Institute of Technology, Pasadena, California, USA.

${ }^{2}$ Now at Jet Propulsion Laboratory, California Institute of Technology, Pasadena, California, USA.

${ }^{3}$ Department of Geological Sciences, Arizona State University, Tempe, Arizona, USA.
}

Copyright 2006 by the American Geophysical Union. 0148-0227/06/2005JE002671 soils and outcrop are also affected by contributions from surface dust [Christensen et al., 2004] and atmospheric radiance [Smith et al., 2004], complicating mineralogic interpretation of these surfaces.

[3] In this work, we analyze over 15,000 individual MiniTES spectra acquired on the MER Opportunity rover and apply factor analysis and target transformation techniques to isolate the major scene spectral end-members present at Meridiani Planum. Factor analysis is a widely used technique [Malinowski, 1991; Bandfield et al., 2000a, 2002] that can determine the number of independent linear components present in a system of mixed spectra. Target transformation allows for the separation of end-members from a mixed spectral data set in which the components combine linearly [Malinowski, 1991; Bandfield et al., 2000a]. We determined that the Mini-TES data set acquired at Meridiani Planum can be accurately modeled using seven end-members: basaltic sand, surface dust similar to the globally homogenous dust observed by MGS-TES, coarsely crystalline hematite, silica/sulfate-rich outcrop, two atmospheric shapes, and blackbody (unit emissivity at all wavelengths).

\section{Methods}

\subsection{Instrument Description}

[4] The Mini-TES instrument is a Michelson interferometer equipped with a $\mathrm{KBr}$ beam splitter and an uncooled pyroelectric deuterated triglicine sulfate (DTGS) detector. It measures spectral radiance from 339 to $1997 \mathrm{~cm}^{-1}$ (5$29 \mu \mathrm{m})$ at 20 or $8 \mathrm{mrad}$ angular spatial resolution and $10 \mathrm{~cm}^{-1}$ spectral sampling [Christensen et al., 2003]. The noise equivalent delta radiance $(\mathrm{NE} \Delta \mathrm{R})$ is similar to pre- 

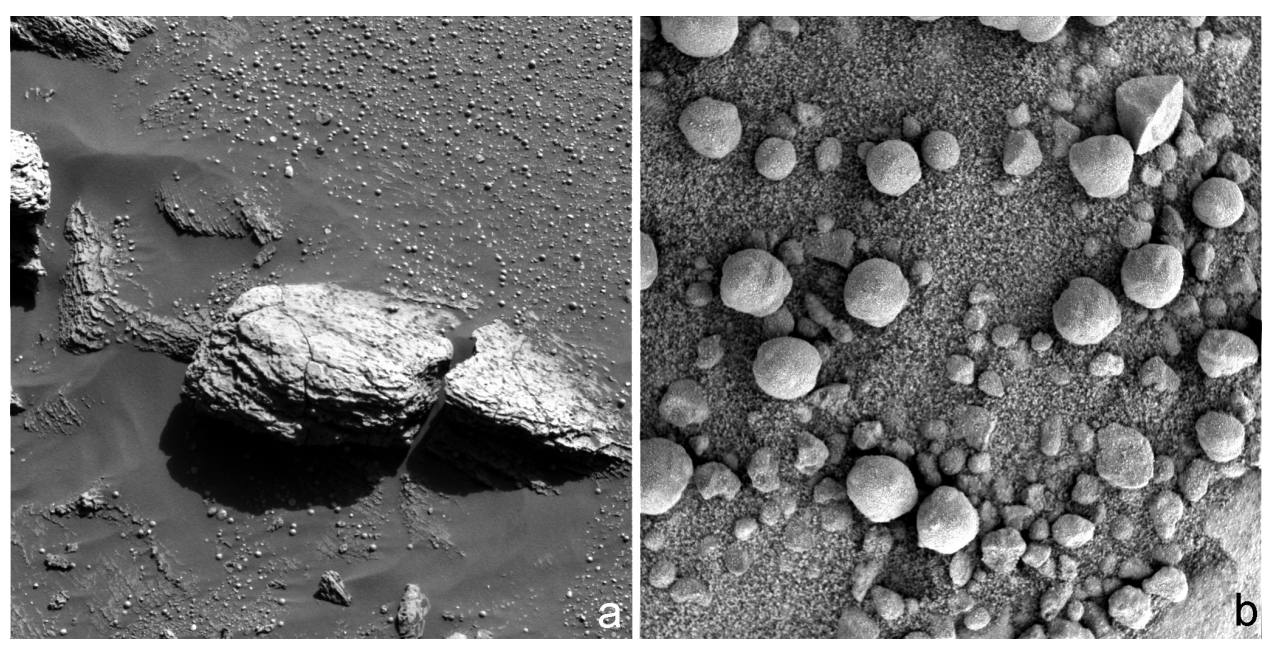

Figure 1. Light-toned outcrop, sand, and spherules, each of which has a distinct mid-IR spectral as seen by Mini-TES. (a) Pancam image 1P129421450RAD0300P2550R1C1 acquired on Sol B14, showing the light-toned outcrop target "Snout," and surrounding basaltic sand and spherules. (b) Microscopic Imager image 1M135729716EFF1400P2956M2F1 of feature Baseball_Phys acquired on Sol B85. This image shows fine basaltic sand with overlying spherules and smaller pebbles. The image is $3 \mathrm{~cm}$ across.

launch values of $\pm 1.8 \times 10^{-8} \mathrm{~W} \mathrm{~cm} \mathrm{sr}^{-1} \mathrm{~cm}^{-1}$ between 450 and $1500 \mathrm{~cm}^{-1}$ for two spectral scan summing. The radiometric precision is reduced to $\sim 4.2 \times$ $10^{-8} \mathrm{~W} \mathrm{~cm}^{-2} \mathrm{sr}^{-1} \mathrm{~cm}^{-1}$ at longer and shorter wavelengths [Christensen et al., 2003; 2004]. The gradual change of the instrument response function over the course of the mission combined with the failure of temperature sensors on the onboard calibration targets has necessitated a change in the approach to the instrument calibration. Details of preflight instrument calibration and calibration at Meridiani Planum are given by Christensen et al. [2003, manuscript in preparation, 2006], respectively.

\subsection{Data Set}

[5] Data from the start of the mission through Sol 350 were used for this work. The observations used include long-dwell (100-200 individually acquired spectra) stares at specific rock and soil targets and rasters of various sizes and dwells. Observations with elevation angles $<-20^{\circ}$ were chosen to prevent the introduction of emission phase angle effects [Calvin et al., 2006]. All observations used for this work were acquired in the nominal 20 mrad mode. Starting around Sol 300, dust began to accumulate on the Mini-TES optics, complicating observations of surface emissivity. The effect on our data set subset is negligible, as Mini-TES observations used in this study extend only to Sol 350 and the dust accumulation was small. In addition, the spectral shape of the dust on the Mini-TES optics resembles the atmospheric dust spectrum, and can be approximated as a linear component (Christensen et al., manuscript in preparation, 2006).

[6] The Mini-TES data have a lower signal-to-noise ratio (SNR) at the longest and shortest wavelengths of spectral coverage. Of the 167 samples that make up a raw Mini-TES spectrum, only samples 5-27 and 43-117 (corresponding to $380-599$ and $759-1498 \mathrm{~cm}^{-1}$ ) were used in the primary study, ensuring high SNR and avoiding the fundamental $\mathrm{CO}_{2}$ absorption centered at $667 \mathrm{~cm}^{-1}$. We also conducted a second trial case in which we used samples 5-27 and 43130 (sample 130 is at $1628 \mathrm{~cm}^{-1}$ ) in order derive the short wavelength spectral shape of the globally homogenous Martian dust.

[7] The light-toned outcrop spectral shape was recovered using a subset $(\sim 10,000$ spectra $)$ of the primary data set. This subset was composed largely of long-dwell stares and rasters that contained significant areal coverage of the outcrop. Because of the relatively few spectra that covered the outcrop and the low spectral contrast of the surfaces, the outcrop spectrum was not as clearly separated from the primary data set. It was, however, a significant component of the subset, and was successfully recovered.

\subsection{Factor Analysis and Target Transformation}

[8] The factor analysis technique can be applied to any data set in which the components of the data set vary independently and the measurements within the data set can be expressed as a linear sum of the components. Because thermal infrared spectra of mineral components combine linearly [Gillespie, 1992; Thomson and Salisbury, 1993; Ramsey and Christensen, 1998], the TES and MiniTES data sets can be analyzed using this technique. Atmospheric radiance adds to surface radiance nonlinearly, but this effect can be approximated as a linear combination for relatively warm surfaces [Bandfield et al., 2000a]. In addition, fine particulate components add nonlinearly, and in deconvolution can affect abundance estimates, but because only spectral shapes are being recovered in this work, this is not an issue.

[9] We apply R-mode factor analysis by transforming the column-oriented data matrix (spectra) into eigenvectors with associated eigenvalues. Using the method of Bandfield et al. [2000a], the data matrix factorization is covariance rather than correlation based. The eigenvalues associated with each eigenvector indicate the relative importance of the eigenvectors with respect to the total variation in the scene. For a system that has a finite number of components, the 
eigenvalues also indicate which eigenvectors represent real components, and which represent random noise. Because a linear combination of components is assumed, any nonlinearity within the system will complicate the result and add to the number of interpreted components. The total number of recoverable eigenvectors is the same as the number of spectral samples in the data (98 or 117 for the Mini-TES data presented here). In practice, however, the eigenvalues are used to constrain which eigenvectors represent the true variation in the scene, reducing the dimensionality, and therefore complexity, of the data matrix. The details of the methods used to perform the eigenvector transformation are given by Malinowski [1991].

[10] The derived eigenvectors represent meaningful variability within a data set, but they are orthogonal and abstract and must be transformed into physically meaningful components. This is accomplished by the target transformation process, which transforms, or rotates, the coordinate axes of the abstract matrices, and aligns them in a fashion that yields a physically meaningful vector. From a practical standpoint, this is accomplished by performing a linear least squares fit of the eigenvectors onto a test vector that is thought to be a component of the system. If the best fit spectrum is an acceptable match to the test spectrum, then it is a component in the data being analyzed. On occasion, cases arise in which it is difficult or impossible to select an appropriate target vector for a component that is present in the system. For these cases, if many target vectors are tested, and a particular shape is recovered with consistency throughout the set of target vectors, then that best fit shape is reliably a component of the system even though it was not a match to any particular target vector. [Bandfield et al., 2000a]. Selected target endmember spectra can be verified by ensuring that unrealistic emissivity values (i.e., greater than unity) are not present, each selected end-member is not a linear combination of other end-members present, and that weightings from a least squares fit of each end-member to the set of mixed spectra are nonnegative.

\section{Results}

\subsection{Recovery of Eigenvectors and Eigenvalues}

[11] The factor analysis and target transformation techniques were performed on three subsets of the Mini-TES data over spectral ranges of $380-1498 \mathrm{~cm}^{-1}$ (case 1) and $380-1628 \mathrm{~cm}^{-1}$ (case 2) for the primary data set and $380-$ $1498 \mathrm{~cm}^{-1}$ (case 3) for the reduced data set used to determine the spectral shape of the outcrop. Following the methods of Bandfield et al. [2000a], the mean of the data set is removed prior to the determination of eigenvectors and eigenvalues and is taken as the first component. Additional eigenvectors represent variations within the mean-removed data set. Thus the number of components in the system is the number determined by factor analysis plus one. Earlier work [Rozett and Peterson, 1975] showed no significant difference between the interpretations of a data set with and without the mean removed.

[12] In each case presented here, data from 598-758 $\mathrm{cm}^{-1}$ were excluded due to the presence of the fundamental $\mathrm{CO}_{2}$ absorption centered at $667 \mathrm{~cm}^{-1}$. The principal eigenvectors and their associated eigenvalues for each case are shown in
Figure 2. The eigenvalues represent the total variation within a data set and should only be used to judge the relative importance of eigenvectors within a data set. Because cases 1-3 contain different numbers of spectra and spectral samples, the magnitudes of eigenvalues from one case do not directly correspond to those in other cases.

[13] Observation of the eigenvalues alone indicates that there should be four components in the first and third cases, and five components in the second. However, there is some spectral character in higher-order eigenvectors, indicating that the factor analysis algorithm is having some difficulty separating lower-order components from noise. Factor analysis cannot distinguish between scene spectral components and other systematic components such as changing instrument response function or slopes that may be present in the spectra. These components add complexity to the system, so intelligent user intervention is required to interpret the data set.

[14] The higher-order eigenvectors vary in their nature for each case (Figure 2). For case 1, in which the spectral range extends to $1498 \mathrm{~cm}^{-1}$ of the primary data set, the sixth eigenvector displays some long wavelength spectral character. The seventh through tenth eigenvectors all show increased noise at the shortest wavelengths. For case 2, in which the spectral range is extended to $1628 \mathrm{~cm}^{-1}$, the fifth eigenvector is dominated by short wavelength noise, while eigenvectors 6 and 7 have long wavelength spectral character. Eigenvectors 8-10 are similar to the fifth eigenvector; they are flat through most of the wavelength range, with increased noise at the shortest wavelengths. All the eigenvectors determined for case 3 , which consists of a reduced data set, show some spectral character at long wavelengths, with eigenvectors $8-10$ showing the least spectral character. The first seven eigenvectors all show significant structure, though it is hard to determine from the eigenvalues which eigenvectors should be significant. For all cases, there is no obvious way to determine the number of scene spectral components based on the eigenvalues and eigenvectors, although a reasonable estimate would place the number of components in each system at between five and seven. Target transformation will be used to determine the number of components, as the number of recoverable spectral shapes determines the number of scene components present in the system.

\subsection{Recovered Spectral Shapes \\ 3.2.1. Hematite}

[15] Figure 3a shows the hematite spectrum recovered from the Mini-TES data using a goethite-derived hematite [Glotch et al., 2004] target vector. There is a good fit in terms of band shapes and positions, although the relative depths of the two major absorption bands are slightly different from the test spectrum. Figure $3 \mathrm{~b}$ shows the Mini-TES hematite spectrum recovered using a magnetitederived hematite [Glotch et al., 2004] target spectrum. There is a poor fit to the $\sim 450 \mathrm{~cm}^{-1}$ band width and position of the emissivity minimum. Additionally, there is a poor fit to the $390 \mathrm{~cm}^{-1}$ feature that is present in the test spectrum. These results demonstrate that the spectra of the hematite at Meridiani Planum do not exhibit a $390 \mathrm{~cm}^{-1}$ feature, and the best match to the Martian hematite spectrum is that of a goethite-derived hematite [Glotch et al., 2004]. 

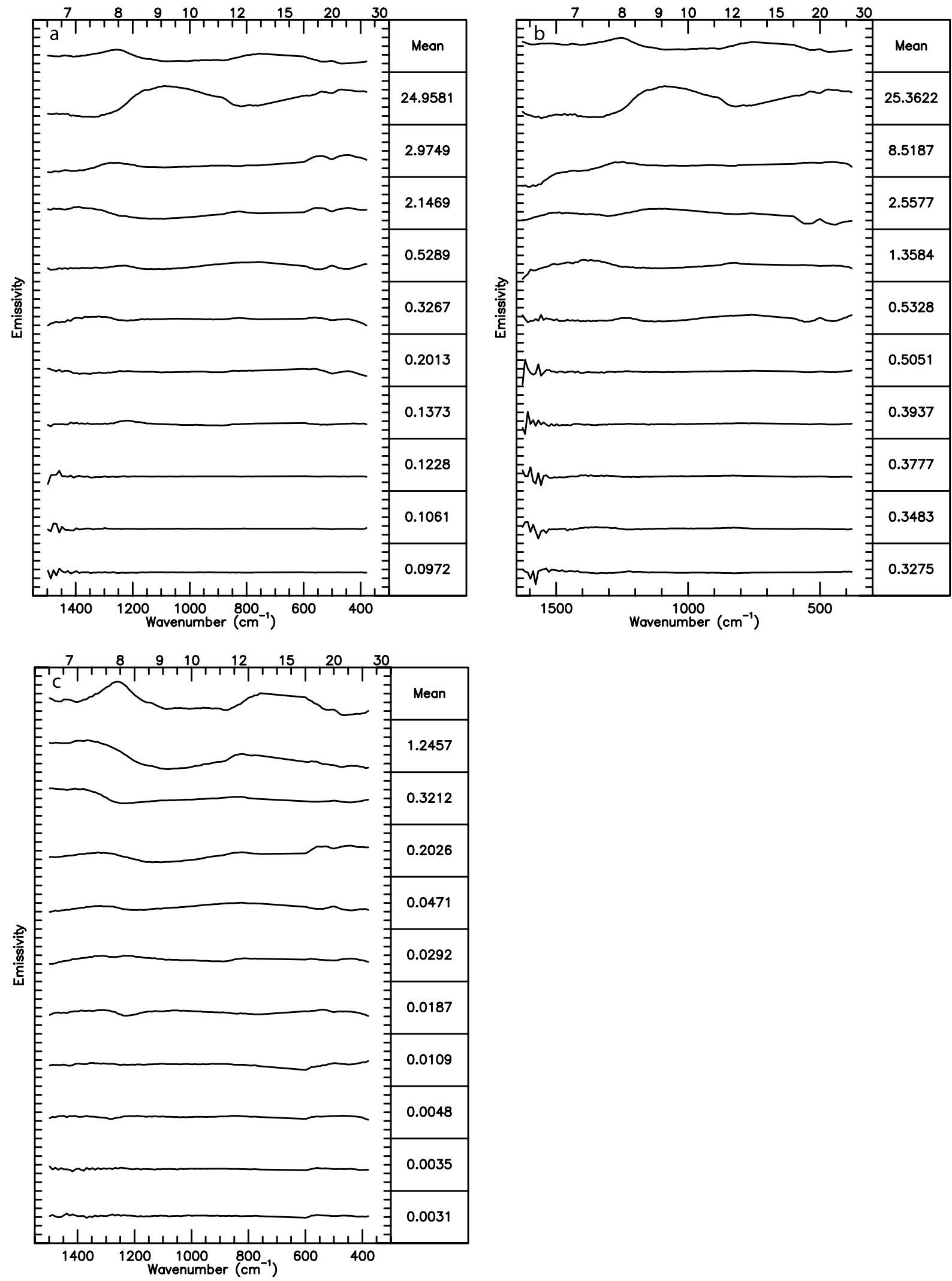

Figure 2. The mean and first 10 eigenvectors determined for the Mini-TES data set using factor analysis. Eigenvalues associated with each eigenvector are also displayed. (a) Case 1 mean and eigenvectors determined from full data set from 380-599 and 759-1498 $\mathrm{cm}^{-1}$. (b) Case 2 mean and eigenvectors determined from full data set from 380-599 and 759-1628 $\mathrm{cm}^{-1}$. (c) Case 3 mean and eigenvectors determined from data limited to stares on outcrops and surrounding terrains. The spectral range is $380-599$ and $759-1498 \mathrm{~cm}^{-1}$. 

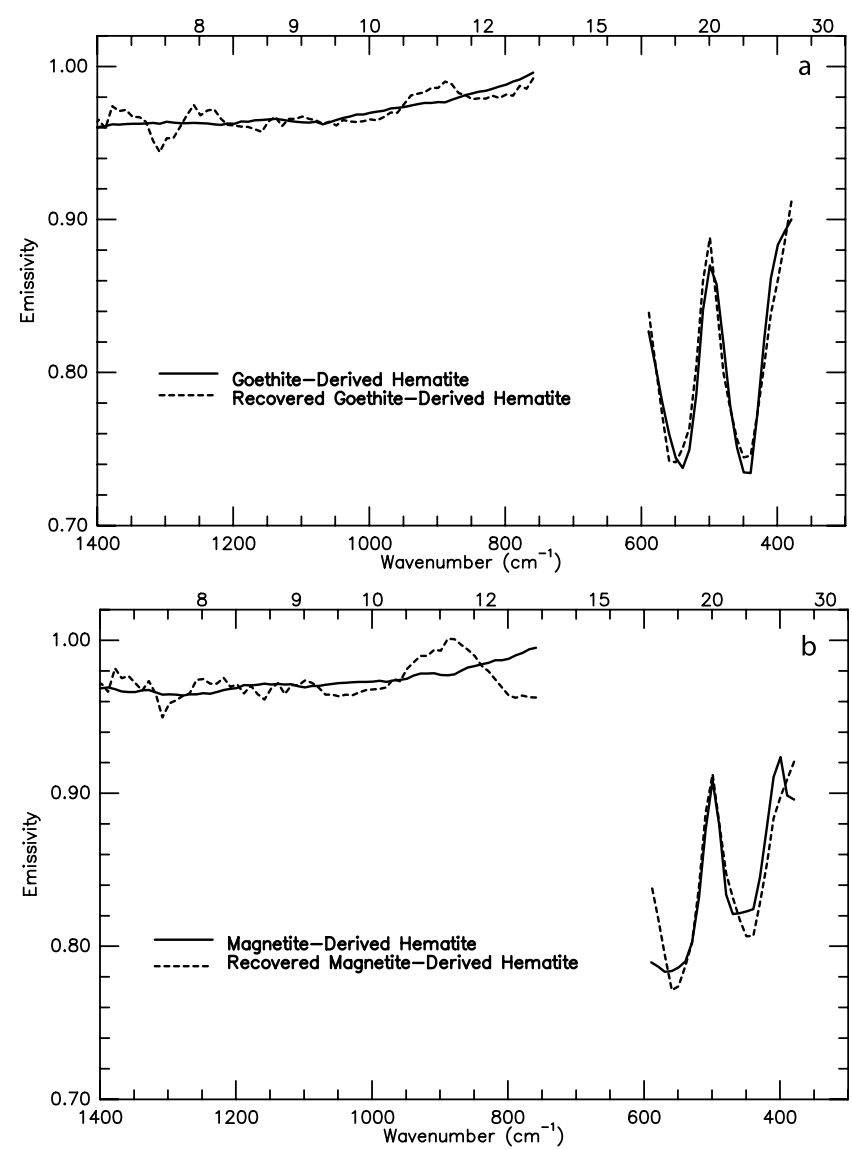

Figure 3. Examples of target transformation derived hematite spectra. (a) Hematite spectrum derived from the Mini-TES data using a goethite-derived hematite as the target spectrum. There is overall good agreement between the target and recovered spectra. (b) Hematite spectrum derived from the Mini-TES data using a magnetite-derived hematite as the target spectrum. There is poor agreement between the target and recovered spectra in terms of band shape, position, and depth. The $390 \mathrm{~cm}^{-1}$ feature in the target spectrum is not accurately reconstructed from the Mini-TES data.

\subsubsection{Basalt}

[16] Another main component of the Meridiani Planum surface is basaltic sand (Figure 4a). This ubiquitous sand, imaged by Pancam [Bell et al., 2004], Navcam, and the Microscopic Imager [Herkenhoff et al., 2004] (Figure 1), has a spectral shape that is similar to the basaltic TES Surface Type 1 (ST1) as seen from orbit. Slight variations from the ST1 spectrum can be seen between $\sim 800$ and $1200 \mathrm{~cm}^{-1}$ and at the lower wave numbers. Because of the thin column of atmosphere through which Mini-TES observations are made, we were able to recover a spectral shape that extends significantly into the region dominated by $\mathrm{CO}_{2}$ in the TES spectrum.

[17] We also attempted to recover a match to the TES Surface Type 2 spectrum (Figure $4 b$ ), which has been interpreted as either a basaltic andesite [Bandfield et al., 2000b] or a weathered basalt [Wyatt and McSween, 2002]. For the regions over which the ST2 and recovered spectra overlap $\left(380-510 \mathrm{~cm}^{-1}\right.$ and $\left.825-1306 \mathrm{~cm}^{-1}\right)$ the match between the recovered spectrum and ST2 is comparable to that for ST1 shown in Figure 4a. However, the regions of the recovered spectrum that do not overlap with ST2 indicate that taking into account only the overlapping regions may be misleading. At long wavelengths, the recovered spectrum displays the spectral characteristics of hematite shown in Figure 3a. The long wavelength portions of the ST2 spectrum does not correspond with the Martian hematite spectral shape derived from TES data [Glotch et al., 2006b]. In addition, previous analyses of the distribution of TES ST2 [Bandfield et al., 2000b; Wyatt and McSween, 2002; Rogers, 2005] have not shown it to correspond exclusively to the hematite-rich regions of Mars. So, the presence of the hematite spectral shape in the recovered Mini-TES spectrum is inconsistent with TES
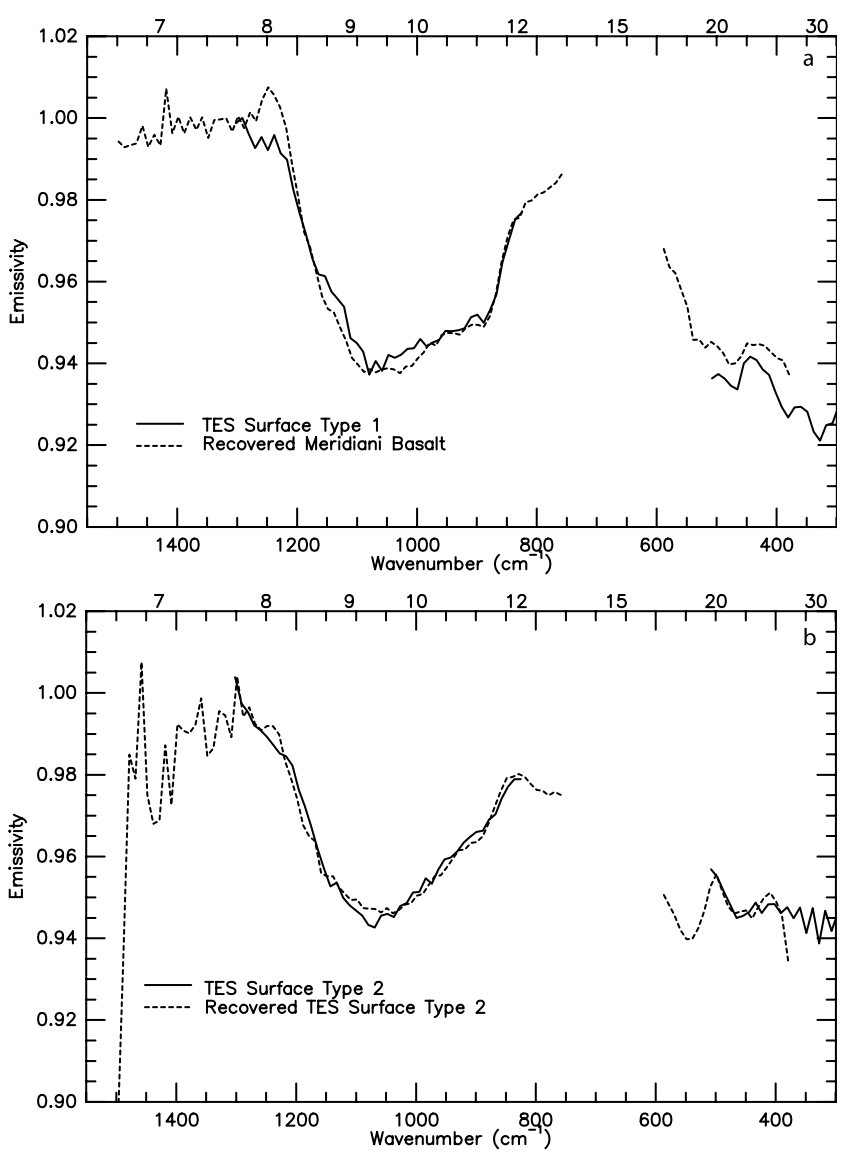

Figure 4. Spectral shapes recovered from the Mini-TES data using TES ST1 and TES ST2 as target spectra. (a) Basalt component derived from the Mini-TES data using TES ST1 (basalt) as the target spectrum. There is good overall agreement between the target and recovered spectra, indicating that basalt is a likely component of the scene observed by Mini-TES at Meridiani Planum. The differences observed at long wavelengths between the target and recovered spectra indicate that the mineralogy of the basalt at Meridiani Planum may deviate from the global average. (b) Spectrum recovered from the Mini-TES data using TES ST2 (basaltic andesite) as the target spectrum. There is poor agreement between the test and recovered spectra, indicating that basaltic andesite is not likely to be a component of the scene observed by Mini-TES at Meridiani Planum. 


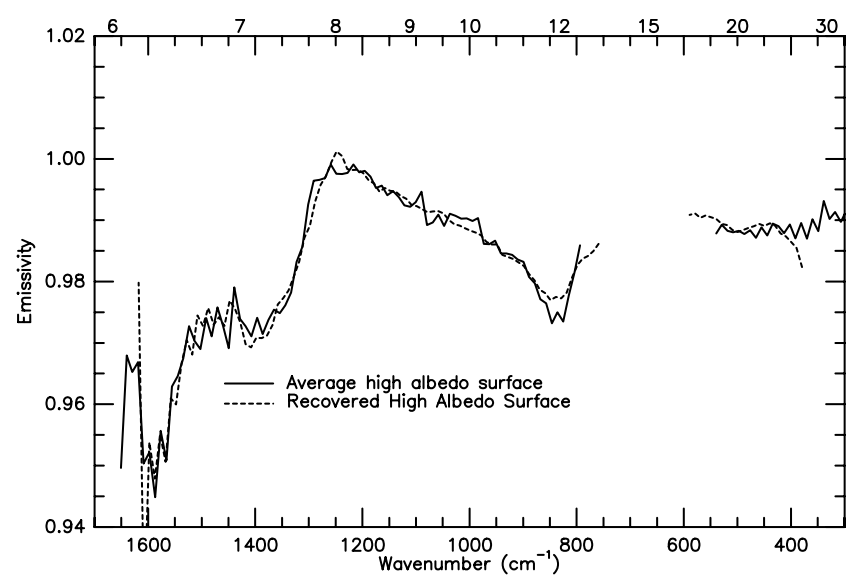

Figure 5. Target and recovered spectra of surface dust. The target spectrum is the average high-albedo region spectrum derived from EPF measurements from TES. There is good agreement between the target and recovered spectra, indicating that the surface dust at Meridiani Planum is similar to the globally homogenous surface dust observed by TES.

ST2. At wavelengths shorter than $1306 \mathrm{~cm}^{-1}$, where the Mini-TES and TES data do not overlap, the recovered MiniTES spectrum is dominated by noise and a drop-off in emissivity corresponding to the spectral shape of fine particulates. By contrast, the recovered ST1 spectrum (Figure 4a) shows a constant high emissivity at these wavelengths, consistent with coarse particulates. Both TES ST1 and ST2 occur in low-albedo regions of Mars, consistent with these phases being present as coarse particulates. These lines of evidence lead us to believe that despite the relatively good match between ST2 and the recovered spectrum in regions of overlap, we have not recovered an acceptable match to ST2, and thus it is not present in appreciable abundances near the Opportunity landing site at Meridiani Planum.

\subsubsection{Globally Homogenous Surface Dust}

[18] Although Meridiani Planum is a classic low-albedo region of Mars, the Mini-TES instrument has detected the signature of fine particulates mixed with the soil (Figure 5). The recovered dust spectrum is similar to the TES global average dust spectrum derived by Bandfield and Smith [2003]. The match is particularly good at the shortest wavelengths, where the signatures of bound water and carbonate are present [Bandfield and Smith, 2003; Bandfield et al., 2003; Ruff, 2004]. The main framework silicate transparency feature between 800 and $900 \mathrm{~cm}^{-1}$ is slightly shallower and broader than the global average dust spectrum, and unlike the global average dust spectrum, the recovered spectrum has a distinct Christiansen frequency at $1250 \mathrm{~cm}^{-1}$. A slight misfit is also seen at the lower wave numbers where the TES global average dust is flat with an emissivity of $\sim 0.99$, and the recovered spectrum has a distinct roll-off to lower emissivity at lower wave numbers, due to the lower SNR for this wave number range.

\subsubsection{Silica/Sulfate-Rich Outcrop}

[19] The spectral shape of the light-toned rocky outcrop was more difficult to recover than the other end-members because of its limited areal concentration in the analyzed data set. In an effort to recover a spectral shape representative of the outcrop, we analyzed a subset of the data which had a higher percentage of spectra that contained the outcrop as a component. Spectra with higher outcrop components were chosen based on analysis of Navcam and Pancam imagery. The eigenvectors derived from this

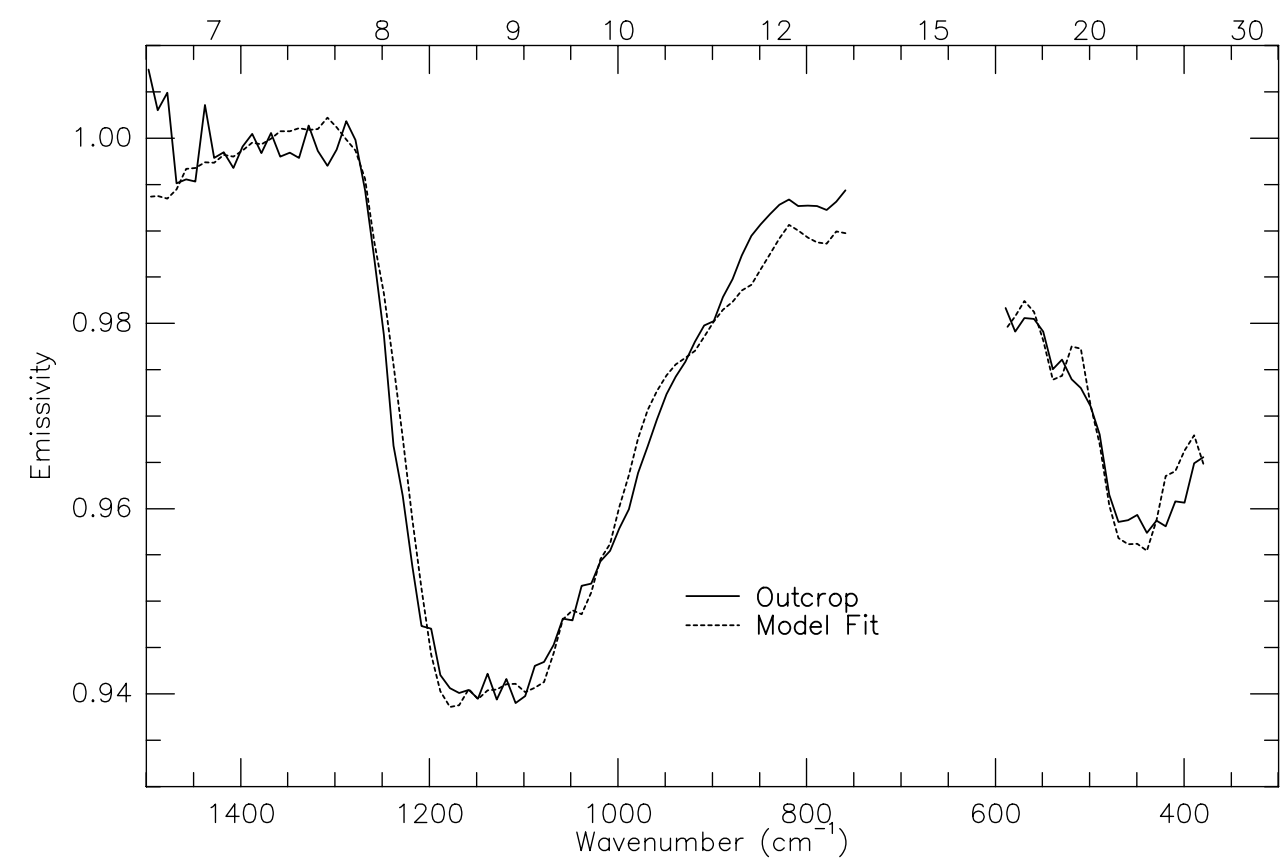

Figure 6. Recovered outcrop spectral shape and model fit from linear deconvolution using library 2 in Table 1. Results from the deconvolution model are shown in Table 3. There is a good overall fit, although small differences indicate that some components of the outcrop may be absent from the spectral library. 
analysis (Figure 2c) were fit to 98 terrestrial rock spectra. No direct matches were found, but one spectral shape was consistently observed (Figure 6). Each occurrence of this spectral shape was isolated, and about 10 recovered spectra were averaged to create the shape shown in Figure 5. This spectrum has realistic emissivity values, is not a combination of any other components, and its presence can be seen in individual spectra in the data set being examined. Thus it is likely an end-member in the system. The modeled mineralogy of the outcrop, which is high in silica and sulfate, is discussed in section 4.3.2. and in much more detail in a companion paper [Glotch et al., 2006b].

\subsubsection{Atmospheric Dust}

[20] An atmospheric component was recovered and is shown in Figure 7a. The target spectrum used for this recovery was the average TES dust opacity spectral shape derived by Bandfield and Smith [2003]. There is good agreement between the Mini-TES and TES spectral shapes and, as with other components, the Mini-TES spectral shape extends further into the region dominated by atmospheric $\mathrm{CO}_{2}$ than the TES shape.

[21] Long-dwell Mini-TES atmospheric stares (elevation angle of $30^{\circ}$ ) were also used as target vectors to test the effect of variable atmospheric conditions on the data set. Because the surface observations that comprise the data set were acquired at many times of day and at various temperatures, it is expected that the atmospheric components of those observations may have varied significantly. Two additional end-member atmospheric spectral shapes can be recovered from the surface observation data set. These are shown in Figures $7 \mathrm{~b}$ and 7c. The atmospheric test vector shown in Figure $7 \mathrm{~b}$ represents an average of 10 atmospheric stares (Mini-TES sequence p3580) acquired between sols 51 and 100. The average band 34 brightness temperature (in the center of the $\mathrm{CO}_{2}$ absorption) is $\sim 250 \mathrm{~K}$. The overall fit of the recovered spectrum to the test vector is good, with the exception of the region between 1050 and $1100 \mathrm{~cm}^{-1}$. In this region, the test spectrum contains $\mathrm{CO}_{2}$ hot bands that are not present in the recovered atmospheric spectrum.

[22] The test spectrum shown in Figure $7 \mathrm{c}$ is an average of 5 p3580 sequences between sols 51 and 100. The average band 34 brightness temperature is $\sim 225 \mathrm{~K}$. There is a pronounced increase in apparent emissivity at wave numbers $>1300 \mathrm{~cm}^{-1}$, that is absent in the test spectrum shown in Figure $7 \mathrm{~b}$. In addition, the fit between 1050 and $1100 \mathrm{~cm}^{-1}$ is better than that shown in Figure $7 \mathrm{~b}$ due to the reduced magnitude of the $\mathrm{CO}_{2}$ hot bands.

\section{Discussion}

\subsection{Hematite}

[23] The hematite component recovered using factor analysis and target transformation is that of pure crystalline hematite comparable to a high-grade laboratory spectrum (Figure 3a). Although we recover a pure hematite spectrum in this work, Jolliff and Athena Science Team [2005] have shown through a mass balance mixing model approach that the spherules at Meridiani Planum (Figure 1) are likely composed of $37-60 \%$ by weight hematite. Additionally, Mössbauer data [Klingelhöfer et al., 2004] have shown that hematite also occurs independently of the spherules within

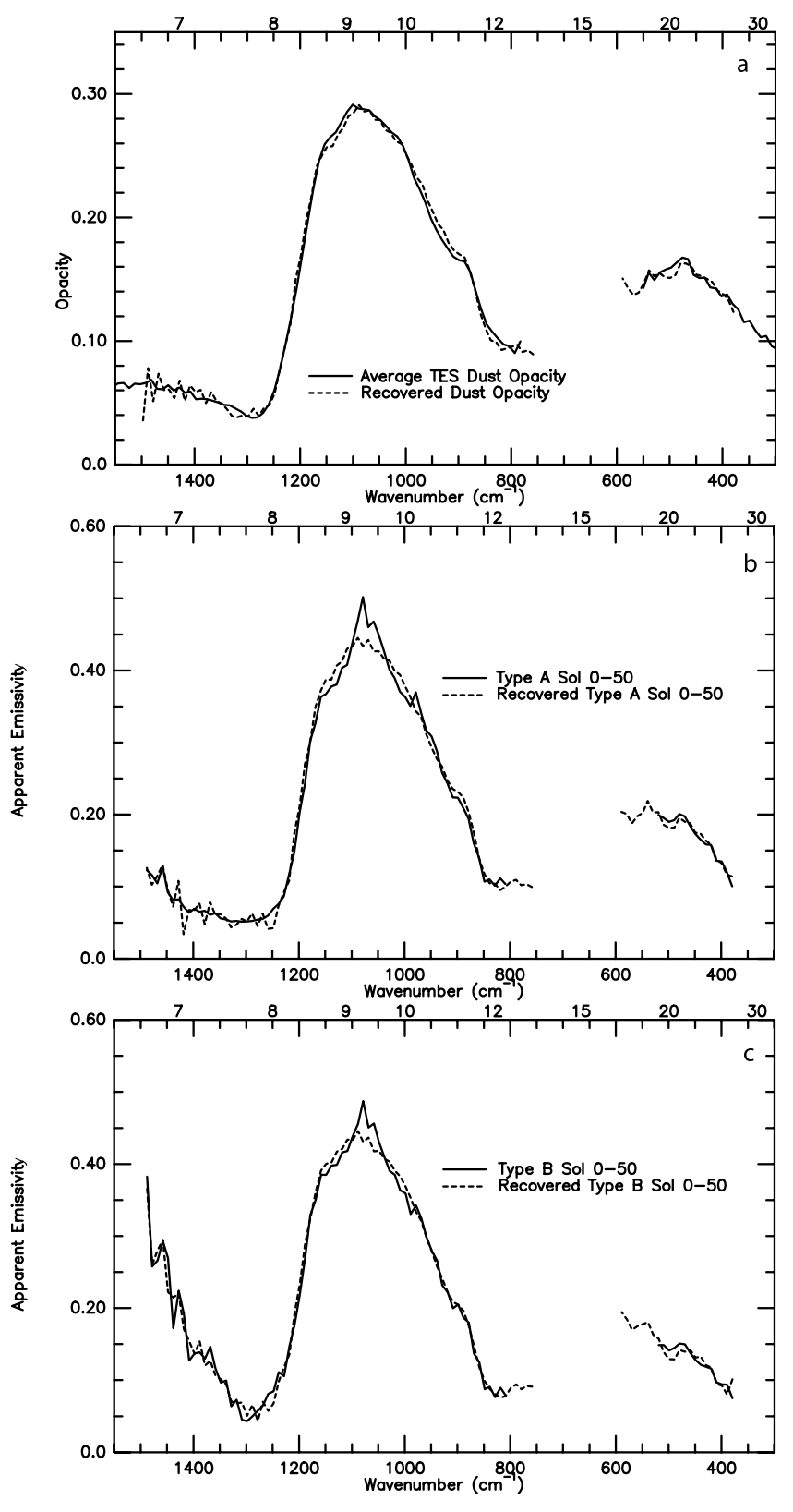

Figure 7. Target and recovered atmospheric spectral shapes. (a) Atmospheric dust opacity using the TES dust opacity spectrum as the target vector. (b) Atmospheric emissivity (type A) recovered using an average of 10 p3580 atmospheric stare sequences as the target vector. The average $669 \mathrm{~cm}^{-1}$ brightness temperature of the p3580 sequences is $\sim 250^{\circ} \mathrm{C}$. (c) Atmospheric emissivity (type B) recovered using an average of 10 p3580 atmospheric stare sequences as the target vector. The average $669 \mathrm{~cm}^{-1}$ brightness temperature of the p3580 sequences $\sim 225^{\circ} \mathrm{C}$.

the light toned outcrop matrix. Thus there are several possible explanations for the recovery of a pure hematite spectrum rather than an average spherule spectrum: (1) The hematite is present only in the form of a coating $>\sim 50 \mu \mathrm{m}$ thick on the spherules. (2) The other components of the spherules are fine particulates difficult to detect with the Mini-TES. (3) Hematite is present not only in the spherules, 
but in the outcrop matrix. (4) The hematite abundance within the spherules varies significantly and independently from the other spherule components. Of these possibilities, we consider scenarios 3 and 4 to be the most likely.

[24] The likelihood of scenario 1, a hematite coating is lessened by the fact that many surfaces have been observed that are dominated by broken spherules [Soderblom et al., 2004] which have a strong hematite signature in Mini-TES spectra. Additionally, although other components in the spherules may be finely crystalline (scenario 2), the spherules are hard and well cemented, and laboratory work has shown that compaction of fine particulates can create a surface with a spectral contrast comparable to coarse particulates [e.g., Roush et al., 1991; Cooper and Mustard, 2002; Glotch et al., 2004]. Outcrop matrix hematite (scenario 3 ), if coarsely crystalline and detectable by the MiniTES, could account for the independently variable nature of hematite in the Mini-TES data set. As discussed in section 4.3.2, a deconvolution model of the outcrop spectral shape includes 5\% hematite, which is just at the detection limit of hematite by the Mini-TES instrument. It will difficult to evaluate if spherule hematite abundance varies significantly (scenario 4) unless experiments similar to the "Berry Bowl" experiment carried out in Eagle crater [Klingelhöfer et al., 2004; Christensen et al., 2004] are performed with some regularity. This scenario, however would easily account for the variability required to recover a pure hematite spectrum.

[25] The recovered hematite spectrum (Figure 3a) shows no evidence of a spectral band at $390 \mathrm{~cm}^{-1}$, as is seen in some terrestrial hematite spectra. The lack of a feature at $390 \mathrm{~cm}^{-1}$ is attributable to [001]-dominated emission, and has been interpreted as due to platy [Lane et al., 2002] or lathy [Glotch et al., 2004] hematite crystal shapes. Additionally, the shapes and positions of the hematite spectral bands are consistent with hematite formed by the lowtemperature dehydroxylation of goethite, which produces lathy hematite crystals [Glotch et al., 2004]. This is also consistent with the presence of the Fe sulfate jarosite in the outcrop matrix, as goethite and jarosite are often associated in nature [Herbert, 1995, 1997] and are easily coprecipitated in the laboratory [Brown, 1971; Stahl et al., 1993]. Hematite formed by high-temperature processes, such as might be found in a volcanic sulfotara environment [e.g., McCollom and Hynek, 2005], or as the result of formation of volcanic lapilli or impact melt spherules [e.g., Knauth et al., 2005], produces a spectrum inconsistent with that seen on Mars [Glotch et al., 2004].

[26] Glotch et al. [2006a] modeled the emission spectra of specular hematite crystal surfaces and determined that roughly $90 \%$ of the total emission must be parallel to the hematite [001] axis for the $390 \mathrm{~cm}^{-1}$ feature to be absent. This finding is consistent with platy or lathy hematite crystal shapes with large (001) faces. Glotch et al. [2006a] proposed two models for the internal structure of the hematite spherules based on the infrared spectra. The spherules could be composed of randomly oriented lathy or platy hematite crystals which would display [001] dominated emission from any viewing angle. Alternatively, the hematiterich spherules may have grown as an anhedral crystal mass with [001] pointing radially in all directions from the center of the spherules. The second possibility is considered less likely given the results of Jolliff and Athena Science Team [2005]. That is, radial symmetry of an anhedral crystal mass would likely be disturbed by the presence of other components within the spherules.

\subsection{Surface Dust and Atmospheric Spectral Shapes}

[27] The dust spectral shape derived from the Mini-TES data at Meridiani Planum is largely similar to that of globally homogenous dust seen from orbit by the TES instrument. There are, however, some small differences. The Mini-TES dust shape has a distinct Christiansen feature while the TES dust shape does not. Additionally, the silicate transparency feature between 800 and $900 \mathrm{~cm}^{-1}$ is slightly shallower and broader in the Mini-TES spectrum than the TES spectrum. These differences may be a result of the influence of locally derived fines from the sulfate-rich outcrop mixing with the globally homogeneous dust. Despite these small differences, the TES and Mini-TES derived dust spectral shapes are largely similar, implying that the fines at Meridiani Planum are related to the Martian globally homogenous dust.

[28] Dust is also present in the atmosphere above Meridiani Planum, and it contributes to the downwelling radiance seen by the Mini-TES instrument. This is evident from Figure $7 \mathrm{a}$, which shows a successful recovery of a spectral shape for which TES dust opacity is the target spectrum. In addition, two distinct atmospheric spectral shapes were recovered (Figures $7 \mathrm{~b}$ and $7 \mathrm{c}$ ) from Mini-TES atmospheric stares which are broadly correlated with the observed brightness temperature in channel $34\left(669 \mathrm{~cm}^{-1}\right)$ of the Mini-TES data, which is in the center of the fundamental $\mathrm{CO}_{2}$ absorption. There are two possibilities regarding the variable atmospheric spectral shapes that are evident in the Mini-TES data. The main difference between the spectra in Figures $7 \mathrm{~b}$ and $7 \mathrm{c}$ is the increased emissivity at $>1350 \mathrm{~cm}^{-1}$ seen in Figure 7c. The spectrum in Figure $7 \mathrm{c}$ is characterized by a channel 34 brightness temperature of $\sim 225 \mathrm{~K}$ as opposed to a temperature of $\sim 250 \mathrm{~K}$ for the spectrum in Figure $7 \mathrm{~b}$. At wave numbers $>\sim 1350 \mathrm{~cm}^{-1}$ the signal from the atmosphere observed by the Mini-TES instrument is quite low, especially for the cold temperature observations. As a result, small systematic errors can greatly affect the spectral shape.

[29] An alternative explanation for the differences seen between the spectra in Figure 7 is related to the surface temperature. Although the spectrum in Figure 7c represents an overall colder atmospheric temperature than the spectrum in Figure $7 b$, if the surface temperatures were warmer when the target spectra that compose the average shown in Figure $7 \mathrm{c}$ were collected, then that increased IR radiation emitted from the surface would lead to more atmospheric scattering, in turn leading to the spectral character seen in Figure $7 \mathrm{c}$ (M. Wolff, personal communication, 2005).

\subsection{Deconvolution of Derived Surface End-Members}

[30] Two of the derived surface end-members, basaltic sand and light-toned outcrop, can be further described by determining their mineralogy by linear deconvolution [Ramsey and Christensen, 1998]. On the basis of knowledge of the chemistry and mineralogy of these surfaces from the APXS, Pancam, and Mössbauer instruments [Rieder et al., 2004; Bell et al., 2004; Klingelhöfer et al., 2004; Clark 
Table 1. End-Member Libraries for Linear Deconvolution of Surface Spectral Shapes

\begin{tabular}{|c|c|}
\hline $\begin{array}{c}\text { Library } 1 \\
\text { (for Deconvolving Basalt Shape) } \\
\end{array}$ & $\begin{array}{c}\text { Library } 2 \\
\text { (for Deconvolving Outcrop Shape) }\end{array}$ \\
\hline Quartz BUR-4120 & Quartz BUR-4120 \\
\hline Anorthite BUR-340 & Anorthite BUR-340 \\
\hline Bytownite WAR-1384 & Bytownite WAR-1384 \\
\hline Labradorite WAR-4524 & Labradorite WAR-4524 \\
\hline Andesine BUR-240 & Andesine BUR-240 \\
\hline Oligoclase BUR-060D & Oligoclase BUR-060D \\
\hline Albite WAR-0244 & Albite WAR-0244 \\
\hline Microcline BUR3460 & Microcline BUR3460 \\
\hline Augite NMNH-9780 & Augite NMNH-9780 \\
\hline Augite NMNH-122302 & Augite NMNH-122302 \\
\hline $\begin{array}{l}\text { Hedenbergite, manganoan } \\
\text { DSM-HED01 }\end{array}$ & $\begin{array}{l}\text { Hedenbergite, manganoan } \\
\text { DSM-HED01 }\end{array}$ \\
\hline Diopside WAR-6474 & Diopside WAR-6474 \\
\hline Enstatite HS-9.4B & Enstatite HS-9.4B \\
\hline Bronzite NMNH-93527 & Bronzite NMNH-93527 \\
\hline Olivine KI 3115 Fo68 ${ }^{\mathrm{a}}$ & Forsterite AZ-01 \\
\hline Olivine KI 3362 Fo60 ${ }^{\mathrm{a}}$ & Fayalite WAR-RGFAY01 \\
\hline Olivine KI 3373 Fo $35^{\mathrm{a}}$ & Actinolite HS-116.4B \\
\hline Olivine KI $3008{\text { Fo } 10^{a}}^{a}$ & Biotite BUR-840 \\
\hline Forsterite AZ-01 & Muscovite WAR-5474 \\
\hline Actinolite HS-116.4B & Chlorite WAR-1924 \\
\hline Biotite BUR- 840 & Serpentine HS-8.4B \\
\hline Muscovite WAR-5474 & Serpentine BUR-1690 \\
\hline Chlorite WAR-1924 & Beidellite SBdl ${ }^{\mathrm{b}}$ \\
\hline Serpentine HS-8.4B & Nontronite Nau- $1^{\mathrm{b}}$ \\
\hline Serpentine BUR-1690 & Nontronite Nau- $2^{\mathrm{b}}$ \\
\hline Beidellite SBdl ${ }^{\mathrm{b}}$ & Hectorite SHCa- ${ }^{\mathrm{b}}$ \\
\hline Nontronite Nau- $1^{\mathrm{b}}$ & Montmorillinite Swy- $1^{\mathrm{b}}$ \\
\hline Nontronite $\mathrm{Nau}-2^{\mathrm{b}}$ & Saponite $\mathrm{Eb}-1^{\mathrm{b}}$ \\
\hline Hectorite SHCa- $1^{\mathrm{b}}$ & Gypsum ML-S6 \\
\hline Montmorillinite Swy-1 ${ }^{\mathrm{b}}$ & Bassanite ML-S7 \\
\hline Saponite Eb- $1^{\mathrm{b}}$ & Anhydrite ML-S9 \\
\hline Gypsum ML-S6 & Glauberite GBYAZ-R1 $^{\mathrm{c}}$ \\
\hline Bassanite ML-S7 & Epsomite $^{\mathrm{d}}$ \\
\hline Anhydrite ML-S9 & $\mathrm{MgSO}_{4}{ }^{\mathrm{d}}$ \\
\hline Kieserite KIEDE $1^{\mathrm{c}}$ & Kieserite KIEDE $1^{\mathrm{c}}$ \\
\hline K-rich glass $\mathrm{e}^{\mathrm{e}}$ & $\begin{array}{l}\text { Natrojarosite LNVJAR1-R1 } \\
\text { perpendicular to lineation }\end{array}$ \\
\hline $\mathrm{SiO}_{2}$ glass $^{\mathrm{e}}$ & Alunite WD $151^{\mathrm{b}}$ \\
\hline Amorphous Silica $^{\mathrm{f}}$ & Natroalunite SLBAZ1 ${ }^{\mathrm{b}}$ \\
\hline Goethite GTS2 ${ }^{\mathrm{g}}$ & Recovered Hematite ${ }^{\mathrm{h}}$ \\
\hline Maghemite MCIS10-RS3 ${ }^{\mathrm{c}}$ & Goethite GTS2 $2^{\mathrm{f}}$ \\
\hline Magnetite MTS4 $^{\mathrm{g}}$ & K-rich glass ${ }^{\mathrm{e}}$ \\
\hline Calcite $\mathrm{C} 27$ & $\mathrm{SiO}_{2}$ glass $\mathrm{e}$ \\
\hline Dolomite C28 & Amorphous Silica $^{\mathrm{f}}$ \\
\hline $\begin{array}{l}\text { aprovided by V. E. Hamilton. } \\
{ }^{\mathrm{b}} \text { Michalski et al. [2005]. } \\
{ }^{\mathrm{c}} \text { Provided by R. V. Morris. } \\
{ }^{\mathrm{d}} \text { Provided by A. Baldridge. } \\
{ }^{\mathrm{e}} \text { Wyatt et al. [2001]. } \\
{ }^{\mathrm{f}} \text { Provided by M. D. Kraft. } \\
{ }^{\mathrm{g}} \text { Glotch et al. [2004]. } \\
{ }^{\mathrm{h}} \text { This work. }\end{array}$ & \\
\hline
\end{tabular}

et al., 2005; McLennan et al., 2005], the end-member libraries were chosen with the known constituents in mind. The end-member library used to deconvolve the basaltic spectral shape is composed primarily of igneous silicate minerals in addition to several carbonate, sulfate, clay, and oxide spectra. The end-member library used to deconvolve the outcrop was similar to the basaltic sand library, but several additional $\mathrm{Mg}$-, $\mathrm{Ca}$-, and Fe-bearing sulfates and amorphous silica and glass components were added to the library with the knowledge that a major component of the outcrop is sulfate. The mineral end-members used to deconvolve the basaltic sand and the outcrop spectra are listed in Table 1.

\subsubsection{Basaltic Sand}

[31] The derived mineralogy of the Meridiani basaltic sand and that of TES Surface Type 1 (ST1) are shown in Table 2. Both spectra are fit well (Figure 8), with spectral RMS emissivity errors of $0.186 \%$ and $0.174 \%$ for the MiniTES and ST1 spectral shapes respectively. Within a margin of error of $10 \%$, the Mini-TES and ST1 derived mineralogies are identical, although the Mini-TES shape is deconvolved with a significant component $(10 \%)$ of pigeonite. The deconvolution model of the ST1 shape includes no pigeonite, but instead uses other $\mathrm{Ca}$-poor pyroxenes. In addition, the deconvolution of the Mini-TES shape uses a slightly larger component of olivine than deconvolution of ST1 (10\% versus 5\%).

[32] Recent work using TES data [Rogers, 2005] has shown that ST1 and ST2, while accurate global averages, can be further subdivided into 11 spectral shapes with unique global distributions. A source region for one of the shapes derived by Rogers [2005] is eastern Meridiani Planum, which has a shape similar to, but distinct from, ST1. The mineralogy of this unit described by Rogers [2005], and rounded to the nearest 5\% is shown in Table 2 with the mineralogies of the Mini-TES basalt end-member and ST1. All modeled mineral abundances are within 10\% of the derived modal mineralogies for both the Mini-TES basalt and ST1. The mineralogical results of Rogers [2005] were not derived using a pigeonite end-member. A more detailed examination of the composition of the basaltic sand at Meridiani Planum is currently being performed [Rogers et al., 2006], which includes conversion of modeled mineralogy to chemistry to compare with results from the APXS and Mössbauer spectrometer [Rieder et al., 2004; Klingelhöfer et al., 2004; Yen et al., 2005].

[33] Although several lines of evidence strongly suggest aqueous mineral deposition at Meridiani Planum [Christensen et al., 2000, 2001; Squyres et al., 2004; Klingelhöfer et al., 2004; Rieder et al., 2004; Christensen et al., 2004; Glotch et al., 2004; Clark et al., 2005; McLennan et al., 2005; Glotch et al., 2006a], the presence of a nearly pristine basalt component with appreciable olivine content implies a long period of dry conditions in which significant chemical weathering did not occur. Crater counts [Lane et al., 2002] have shown that the surface of Meridiani Planum is approximately 4 Gy old, and has undergone a period of burial and exhumation. Any surface aqueous activity at Meridiani Planum would have had to occur $>4 \mathrm{Ga}$. It is also possible that the aqueous activity was relatively short-lived,

Table 2. Derived Modal Mineralogy of Basaltic Units

\begin{tabular}{lccc}
\hline \multicolumn{1}{c}{ Component } & Mini-TES & TES & TES \\
Basalt, \% & ST1, \% & Meridiani, ${ }^{\text {a } \%}$ \\
\hline Plagioclase & 30 & 30 & 25 \\
Clinopyroxene & 10 & 20 & 25 \\
Orthopyroxene & 0 & 10 & 5 \\
Pigeonite & 10 & 0 & 0 \\
Glass/phyllosilicates & 20 & 10 & 20 \\
Olivine & 10 & 5 & 10 \\
Sulfate & 5 & 5 & 5 \\
Carbonate & 5 & 10 & 10 \\
Other & 10 & 10 & 0 \\
\hline
\end{tabular}

${ }^{\mathrm{a}}$ Mineralogy rounded to nearest 5\% from Rogers [2005, Table 3-2]. 

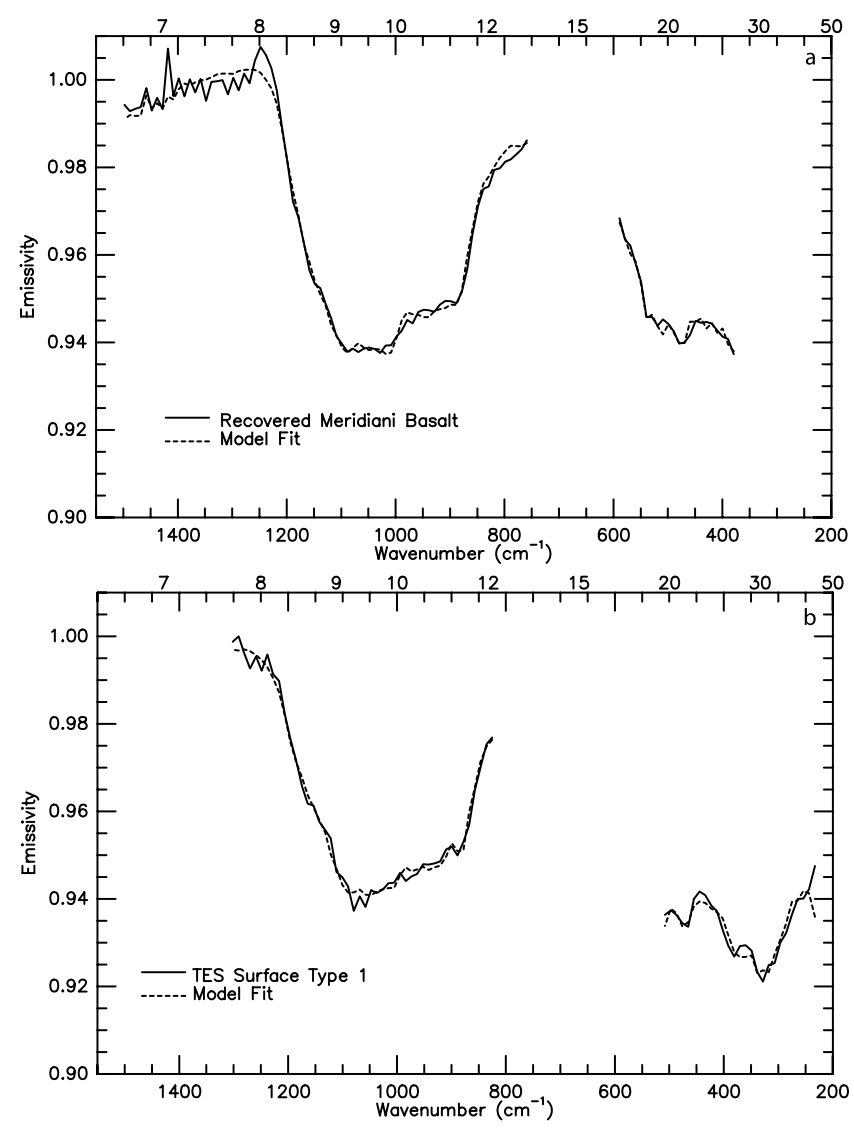

Figure 8. Basaltic spectral shapes and model fits from linear deconvolution using library 1 from Table 1 . Results of the deconvolution model are shown in Table 2. (a) Recovered basaltic shape derived by target transformation from the Mini-TES data set and the model fit. (b) TES ST1 and model fit.

limiting the chemical alteration of the surface, or that the basalt from which the sands were derived was deposited after the period of aqueous activity and subsequently transported to the region, although basaltic sand transport distances are limited to several hundred $\mathrm{km}$ by physical weathering [Edgett and Christensen, 1991; Greeley and Kraft, 2001; Rogers and Christensen, 2003]. To date, the source rock from which the basaltic sands at Meridiani Planum were derived have not been found, so it is difficult to ascertain the chronology of events relating the basaltic and aqueously deposited chemical components.

\subsubsection{Light-Toned Outcrop}

[34] The mineral end-members used to deconvolve the outcrop spectrum are shown in Table 2. The results of the deconvolution of outcrop spectrum are shown in Table 3, and the outcrop spectral shape with the model fit are shown in Figure 6; the RMS emissivity error is $0.307 \%$. Results from the deconvolution indicate that the outcrop is composed primarily of sulfates and amorphous silica/glass/ phyllosilicates. In addition a significant component $(\sim 15 \%)$ of residual silicate minerals is present, wholly in the form of plagioclase feldspar. Finally a small hematite component $(5 \%)$ is present, consistent with the results from the APXS and Mössbauer instruments [Rieder et al., 2004;
Klingelhöfer et al., 2004; Clark et al., 2005; McLennan et al., 2005]. The $\mathrm{Mg}$ - and Ca-bearing sulfates used in the deconvolution are kieserite $\left(\mathrm{MgSO}_{4} \cdot \mathrm{H}_{2} \mathrm{O}\right)$ and anhydrite $\left(\mathrm{CaSO}_{4}\right)$. The deconvolution of the outcrop was a challenging exercise aided by detailed knowledge of the chemistry and iron mineralogy provided by the APXS and Mössbauer instruments. In addition, the mineralogy of the outcrops seen at Meridiani Planum is an important subject with far-reaching implications regarding the past presence of water on Mars. For this reason, a more detailed discussion of the mineralogy of the outcrop as seen by Mini-TES and comparison with the results returned by the other MER instruments can be found in a companion paper [Glotch et al., 2006b].

\section{Conclusions}

[35] The surface of Meridiani Planum, as viewed by the Mini-TES instrument between sols 11-350 is composed of four surface spectral components: silica/sulfate-rich outcrop, basaltic sand, globally homogenous surface dust, and hematite. These surface spectral shapes define the range of variability of the Martian surface at Meridiani Planum, within the detection limit of the Mini-TES instrument. The derived basalt, hematite, and surface dust spectral shapes compare favorably with shapes derived from the orbiting TES instrument, lending confidence to the ability of TES to accurately determine the nature of the Martian surface outside of in situ investigations. In addition, two atmospheric spectral shapes were recovered from the surface stares, which demonstrate the need for adequate surface-atmosphere separation when examining Mini-TES data.

[36] The recovered basalt spectrum is consistent with both TES ST1 [Bandfield et al., 2000b] and a Meridiani Planum shape recovered from the TES data [Rogers, 2005]. There are slight differences between the spectral shapes, but the mineralogical abundances are the same to within $10 \%$. The biggest variations relate to the distributions of pyroxenes and glass/phyllosilicate minerals for each shape.

[37] The hematite spectral shape recovered from the Mini-TES data is similar to that recovered from the TES data [Christensen et al., 2000, 2001; Glotch and Christensen, 2005]. The shape of the spectrum is consistent with the formation of the hematite-rich spherules at low temperature, possibly from an oxyhdroxide precursor such as goethite [Glotch et al., 2004]. This is inconsistent with models for the formation of the outcrop and spherules that require hightemperature volcanic or impact melt environments for the formation of the hematite [e.g., McCollom and Hynek, 2005; Knauth et al., 2005].

Table 3. Derived Mineralogy of the Outcrop Rock at Meridiani Planum

\begin{tabular}{lc}
\hline End-Members & Modeled Mineralogy, \% \\
\hline Silica/glass & 25 \\
Nontronite & 10 \\
Jarosite & 10 \\
Mg sulfate & 20 \\
Ca sulfate & 10 \\
Plagioclase & 15 \\
Fe oxides & 5 \\
Other & 5 \\
RMS & 0.307 \\
\hline
\end{tabular}


[38] The light-toned outcrop observed at Meridiani Planum has a distinct spectral signature that is consistent with the presence of amorphous silica, $\mathrm{Mg}-, \mathrm{Ca}-$, and Fe-bearing sulfates, nontronite, and plagioclase feldspar. A detailed analysis of the outcrop mineralogy, as seen by Mini-TES is available in a companion paper [Glotch et al., 2006b].

[39] Other than two isolated occurrences (Bounce Rock and an iron-nickel meteorite) the seven end-members recovered in this work describe the range of spectral variability observed by Mini-TES through Sol 350 at Meridiani Planum. These end-members may aid in the search for new materials at Meridiani Planum, as any warm surface that cannot be adequately deconvolved using only them likely has a significantly different spectral shape from anything observed through Sol 350 by the Mini-TES instrument.

[40] Acknowledgments. We thank the science and engineering teams at ASU for the planning and acquisition of Mini-TES data and the MER science and engineering teams for acquisition of all other data used in this manuscript. We also thank Alice Baldridge, Mike Kraft, and Dick Morris, and Vicky Hamilton for the use of unpublished mineral spectra. Mike Smith and Mike Wolff provided helpful discussions regarding the Mini-TES atmosphere observations. F. Scott Anderson and an anonymous reviewer provided helpful formal reviews which improved the content and clarity of the manuscript. This work was performed for the Jet Propulsion Laboratory, California Institute of Technology, sponsored by the NASA.

\section{References}

Arvidson, R. E., F. P. Seelos IV, K. S. Deal, W. C. Koeppen, N. O. Snider, J. M. Kieniewicz, B. M. Hynek, M. T. Mellon, and J. B. Garvin (2003), Mantled and exhumed terrains in Terra Meridiani, Mars, J. Geophys. Res., 108(E10), 8073, doi:10.1029/2002JE001982.

Bandfield, J. L., and M. D. Smith (2003), Multiple emission angle surfaceatmosphere separations of Thermal Emission Spectrometer data, Icarus, $161,47-65$.

Bandfield, J. L., P. R. Christensen, and M. D. Smith (2000a), Spectral data set factor analysis and end-member recovery: Application to analysis of Martian atmospheric particulates, J. Geophys. Res., 105, 9573-9587.

Bandfield, J. L., V. E. Hamilton, and P. R. Christensen (2000b), A global view of Martian surface compositions from MGS-TES, Science, 287, $1626-1630$

Bandfield, J. L., K. S. Edgett, and P. R. Christensen (2002), Spectroscopic study of the Moses Lake dune field, Washington: Determination of compositional distributions and source lithologies, J. Geophys. Res. 107(E11), 5092, doi:10.1029/2000JE001469.

Bandfield, J. L., T. D. Glotch, and P. R. Christensen (2003), Spectroscopic identification of carbonate minerals in the Martian dust, Science, 301, $1084-1087$.

Bell, J. F., III, et al. (2004), Pancam multispectral imaging results from the Opportunity rover at Meridiani Planum, Science, 306, 1703-1708.

Brown, J. B. (1971), Jarosite-goethite stabilities at $25^{\circ} \mathrm{C}, 1$ ATM, Miner. Deposita, 6, 245-252.

Calvin, W. C., T. D. Glotch, R. E. Arvidson, S. Wiseman, J. R. Johnson, S. W. Ruff, A. T. Knudson, and P. R. Christensen (2006), Directional emissivity effects on the Meridiani Plains, Lunar Planet. Sci. [CDROM], XXXVII, Abstract 1481

Christensen, P. R., and S. W. Ruff (2004), The formation of the hematitebearing unit in Meridiani Planum: Evidence for deposition in standing water, J. Geophys. Res., 109, E08003, doi:10.1029/2003JE002233.

Christensen, P. R., et al. (2000), Detection of crystalline hematite mineralization on Mars by the Thermal Emission Spectrometer: Evidence for near-surface water, J. Geophys. Res., 105, 9623-9642.

Christensen, P. R., R. V. Morris, M. D. Lane, J. L. Bandfield, and M. C. Malin (2001), Global mapping of Martian hematite deposits: Remnants of water-driven processes on early Mars, J. Geophys. Res., 106, 23,87323,886 .

Christensen, P. R., et al. (2003), Miniature Thermal Emission Spectrometer for the Mars exploration rovers, J. Geophys. Res., 108(E12), 8064 , doi:10.1029/2003JE002117.

Christensen, P. R., et al. (2004), Mineralogy at Meridiani Planum from the Mini-TES experiment on the Opportunity rover, Science, 306, 17331740.
Clark, B. C., et al. (2005), Chemistry and mineralogy of outcrops at Meridiani Planum, Earth Planet. Sci. Lett., 240, $73-94$.

Cooper, C. D., and J. F. Mustard (2002), Spectroscopy of loose and cemented sulfate-bearing soils: Implications for duricrust on Mars, Icarus, 158, $42-55$.

Edgett, K. S. (2005), The sedimentary rocks of Sinus Meridiani: Five key observations from data acquired by the Mars Global Surveyor and Mars Odyssey orbiters, Mars, 1, 5-58, doi:10.1555/mars.2005. 0002 .

Edgett, K. S., and P. R. Christensen (1991), The particle size of Martian aeolian dunes, J. Geophys. Res., 96, 22,765-22,776.

Edgett, K. S., and T. J. Parker (1997), Water on early Mars: Possible subaqueous sedimentary deposits covering ancient cratered terrain in western Arabia and Sinus Meridiani, Geophys. Res. Lett., 24, $2897-$ 2900

Gillespie, A. R. (1992), Spectral mixture analysis of multispectral thermal infrared images, Remote Sens. Environ., 42, 137-145.

Glotch, T. D., and P. R. Christensen (2005), Geologic and mineralogic mapping of Aram Chaos: Evidence for a water-rich history, J. Geophys. Res., 110, E09006, doi:10.1029/2004JE002389.

Glotch, T. D., R. V. Morris, P. R. Christensen, and T. G. Sharp (2004), Effect of precursor mineralogy on the thermal infrared emission spectra of hematite: Application to Martian hematite mineralization, J. Geophys. Res., 109, E07003, doi:10.1029/2003JE002224.

Glotch, T. D., P. R. Christensen, and T. G. Sharp (2006a), Fresnel modeling of hematite crystal surfaces and application to Martian hematite spherules, Icarus, 181, 408-418.

Glotch, T. D., J. L. Bandfield, P. R. Christensen, W. M. Calvin, S. M. McLennan, B. C. Clark, A. D. Rogers, and S. W. Squyres (2006b), Mineralogy of the light-toned outcrop at Meridiani Planum as seen by the Miniature Thermal Emission Spectrometer and implications for its formation, J. Geophys. Res., 111, E12S03, doi:10.1029/2005JE002672.

Golombek, M. P., et al. (2003), Selection of the Mars Exploration Rover landing sites, J. Geophys. Res., 108(E12), 8072, doi:10.1029/ 2003JE002074.

Golombek, M. P., et al. (2005), Assessment of Mars Exploration Rover landing site predictions, Nature, 436, 44-48.

Greeley, R., and M. D. Kraft (2001), Survivability of aggregate sands on Mars, Lunar. Planet. Sci. [CD-ROM], XXXII, Abstract 1839.

Herbert, R. B., Jr. (1995), Precipitation of Fe oxyhydroxides and jarosite from acidic groundwater, GFF, 117, 81-85.

Herbert, R. B., Jr. (1997), Properties of goethite and jarosite precipitated from acidic groundwater, Dalarna, Sweden, Clays Clay Miner, 45, 261 273

Herkenhoff, K. E., et al. (2004), Evidence from Opportunity's Microscopic Imager for water on Meridiani Planum, Science, 306, 1727-1730.

Hynek, B. M., R. E. Arvidson, and R. J. Phillips (2002), Geologic setting and origin of Terra Meridiani hematite deposit on Mars, J. Geophys. Res. 107(E10), 5088, doi:10.1029/2002JE001891.

Jolliff, B. L., and Athena Science Team (2005), Composition of Meridiani hematite-rich spherules: A mass-balance mixing-model approach, Lunar Planet. Sci. [CD-ROM], XXXVI, Abstract 2269.

Klingelhöfer, G., et al. (2004), Jarosite and hematite at Meridiani Planum from Opportunity's Mössbauer Spectrometer, Science, 306, 17401745.

Knauth, L. P., D. M. Burt, and K. H. Wohletz (2005), Impact origin of sediments at the Opportunity landing site on Mars, Nature, 438, 11231128.

Lane, M. D., R. V. Morris, S. A. Mertzman, and P. R. Christensen (2002), Evidence for platy hematite grains in Sinus Meridiani, Mars, J. Geophys. Res., 107(E12), 5126, doi:10.1029/2001JE001832.

Maki, J. N., et al. (2003), Mars Exploration Rover engineering cameras, J. Geophys. Res., 108(E12), 8071, doi:10.1029/2003JE002077.

Malinowski, E. R. (1991), Factor Analysis in Chemistry, 2nd ed., John Wiley, Hoboken, N. J.

McCollom, T. M., and B. M. Hynek (2005), A volcanic environment for bedrock diagenesis at Meridiani Planum on Mars, Nature, 438, 11291131.

McLennan, S. M., et al. (2005), Provenance and diagenesis of the evaporate-bearing Burns formation, Meridiani Planum, Mars, Earth Planet Sci. Lett., 240, 95-121.

Michalski, J. R., M. D. Kraft, T. G. Sharp, L. B. Williams, and P. R. Christensen (2005), Mineralogical constraints on the high-silica Martian surface component observed by TES, Icarus, 174, 161-177.

Ramsey, M. S., and P. R. Christensen (1998), Mineral abundance determination: Quantitative deconvolution of thermal emission spectra, J. Geophys. Res., 103, 577-596.

Rieder, R., et al. (2004), Chemistry of rocks and soils at Meridiani Planum from the alpha particle X-ray spectrometer, Science, 306, $1746-1749$. 
Rogers, A. D. (2005), Spatial and stratigraphic variations in Martian surface mineralogy determined from orbital thermal infrared data: Implications for upper crustal evolution and alteration, Ph.D. dissertation, Ariz. State Univ., Tempe.

Rogers, A. D., O. Aharonson, T. D. Glotch, and P. R. Christensen (2006), Mineralogy of basaltic sands at Meridiani Planum from the Miniature Thermal Emission Spectrometer and comparison to orbital observations, Lunar Planet. Sci. [CD-ROM], XXXVII, Abstract 2273.

Rogers, D., and P. R. Christensen (2003), Age relationship of basaltic and andesitic surface compositions on Mars: Analysis of high-resolution TES observations of the northern hemisphere, J. Geophys. Res., 108(E4), 5030, doi:10.1029/2002JE001913.

Roush, T., J. Pollack, and J. Orenberg (1991), Derivation of midinfrared $(5-25 \mu \mathrm{m})$ optical constants of some silicates and palagonite, Icarus, 94, $191-208$

Rozett, R. W., and E. M. Peterson (1975), Methods of factor analysis of mass spectra, Anal. Chem., 47, 1301-1308.

Ruff, S. W. (2004), Spectral evidence for zeolite in the dust on Mars, Icarus, 168, 131-143.

Smith, M. D., et al. (2004), First atmospheric science results from the Mars Exploration Rovers Mini-TES, Science, 306, 1750-1753.

Soderblom, L. A., et al. (2004), Soils of Eagle Crater and Meridiani Planum at the Opportunity Rover landing site, Science, 306, 1723-1726.
Squyres, S. W., et al. (2004), The Opportunity Rover's Athena science investigation at Meridiani Planum, Mars, Science, 306, 1698-1702.

Stahl, R. S., D. S. Fanning, and B. R. James (1993), Goethite and jarosite precipitation from ferrous sulfate solutions, Soil. Sci. Soc. Am. J., 57 , $280-282$.

Thomson, J. L., and J. W. Salisbury (1993), The mid-infrared reflectance of mineral mixtures (7-14 $\mu \mathrm{m})$, Remote Sens. Environ., 43, 1-13.

Wyatt, M. B., and H. Y. McSween Jr. (2002), Spectral evidence for weathered basalt as an alternative to andesite in the northern lowlands of Mars, Nature, 417, 263-266.

Wyatt, M. B., V. E. Hamilton, H. Y. McSween Jr., P. R. Christensen, and L. A. Taylor (2001), Analysis of terrestrial and Martian volcanic compositions using thermal emission spectroscopy: 1. Determination of mineralogy, chemistry, and classification strategies, J. Geophys. Res., 106, $14,711-14,732$

Yen, A. S., et al. (2005), An integrated view of chemistry and mineralogy of Martian soils, Nature, 436, 49-54.

J. L. Bandfield, Department of Geological Sciences, Arizona State University, Tempe, AZ 85287-6305, USA.

T. D. Glotch, Jet Propulsion Laboratory, California Institute of Technology, MC 150-21, Pasadena, CA 91109, USA. (tglotch@gps.caltech. edu) 